\title{
Preference between Individual Products and Bundles: Effects of Complementary, Price, and Discount Level in Portugal
}

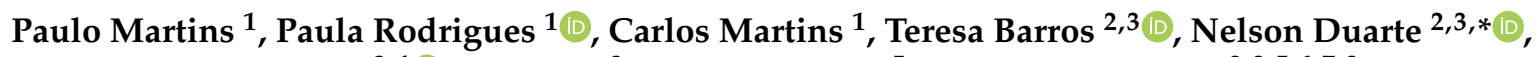 \\ Rebecca Kechen Dong ${ }^{3,4}{ }^{\mathbb{D}}$, Yiyi Liao ${ }^{3}$, Ubaldo Comite ${ }^{5}$ and Xiaoguang Yue $2,3,5,6,7,8$ \\ 1 Faculty of Economics and Management, Universidade Lusíada, Norte, 4369-006 Porto, Portugal; \\ paulo555martins@gmail.com (P.M.); paula_rodrigues@por.ulusiada.pt (P.R.); \\ carlosmartins.office@gmail.com (C.M.) \\ 2 CIICESI-ESTG, Politécnico do Porto, 4610-156 Felgueiras, Portugal; tbarros@estg.ipp.pt (T.B.); \\ x.yue@external.euc.ac.cy (X.Y.) \\ 3 International Research Institute for Economics and Management, Hong Kong, China; \\ rebecca.dong@unisa.edu.au (R.K.D.); Yiyi.liao@hotmail.com (Y.L.) \\ 4 School of Management, University of South Australia, Adelaide 5001, Australia \\ 5 Department of Business Sciences, University Giustino Fortunato, 82100 Benevento, Italy; \\ ubaldo.comite@unical.it \\ 6 Department of Computer Science and Engineering, School of Sciences, European University Cyprus, \\ Nicosia 1516, Cyprus \\ 7 Rattanakosin International College of Creative Entrepreneurship, Rajamangala University of Technology \\ Rattanakosin, Nakhon Pathom 73170, Thailand \\ Citation: Martins, Paulo, Paula \\ Rodrigues, Carlos Martins, Teresa \\ 8 School of Domestic and International Business, Banking and Finance, Romanian-American University, \\ 012101 Bucharest, Romania \\ * Correspondence: nduarte@estg.ipp.pt
} Barros, Nelson Duarte, Rebecca Kechen Dong, Yiyi Liao, Ubaldo Comite, and Xiaoguang Yue. 2021. Preference between Individual Products and Bundles: Effects of Complementary, Price, and Discount Level in Portugal. Journal of Risk and Financial Management 14: 192. https: / / doi.org/10.3390/jrfm14050192

Academic Editor: Thanasis Stengos

Received: 24 February 2021

Accepted: 13 April 2021

Published: 22 April 2021

Publisher's Note: MDPI stays neutral with regard to jurisdictional claims in published maps and institutional affiliations.

Copyright: (c) 2021 by the authors. Licensee MDPI, Basel, Switzerland. This article is an open access article distributed under the terms and conditions of the Creative Commons Attribution (CC BY) license (https:/ / creativecommons.org/licenses/by/ $4.0 /)$.

\begin{abstract}
This paper aims to (1) compare consumers' preferences between individual products and bundles as well as (2) investigate some of the factors involved in bundle characteristics that may affect consumer's preferences. Those factors are complementarity, price level, and discount level. An online survey developed by means of questionnaires were collected from the Portuguese population. Student's $t$-tests were used to test the hypothesis formulated and to analyze the consumers' preferences. The findings corroborate that in a scenario where the bundle does not offer any discounts, preference of individual products is higher. When a $20 \%$ discount is assigned to bundles, the overall preference for individual products is still superior. By offering a discount level of $45 \%$, the overall preference for bundles becomes higher. The positive effect of complementarity bundles valuation is confirmed. This is the first approach to evaluate the preferences between bundles and individual products in the Portuguese market. The findings contribute to clarify the customer map within a Business Model Canvas. Furthermore, this paper analyzes the bundle complementarity and discount level effects simultaneously.
\end{abstract}

Keywords: bundle; bundling; individual products; complementary; price; discount

\section{Introduction}

How to increase profits is an everlasting question in business. Developing new products entails substantial efforts, and the improvement of profits by sales and bundling is one relevant sales strategy for companies (Ye et al. 2017).

Bundling is when two or more products are offered as a single unit and at price lower than the sum of the individual prices of the products (Stremersch and Tellis 2002).

Bundling is the popular marketing strategy of sale of two or more separate products or services in one package (Stremersch and Tellis 2002). In other words, bundling is a marketing technique of selling two or more separate products together in the same package (Stremersch and Tellis 2002). This is a common sales format on numerous industries as 
technology, banking, travel agencies, telecommunications, airline companies, information goods, and even more. In some markets, it is so pervasive that is almost the major used selling format. In the telecommunications industry, dual-play, triple-play, and quadrupleplay bundles command 70\% of subscription revenues (Kopczewski et al. 2018).

Although product bundling is defined as integrated products that give additional value to customers (such as the new car with extra features), price bundling refers to packages sold at a discount without any integration of the goods and services involved (such as a pack of several beers) (Vamosiu 2017). This paper is the first approach to evaluate the preferences between bundles and individual products in the Portuguese market. This is also an option that should be considered in a customer's value map analysis, within a business model canvas, since the data from this strategy, when combined with new technologies, might bring value for retail decision-making (Epstein et al. 2021). The evaluation of a product bundle presents a more complicated decision-making context than evaluating individual products, given the possibility of interactions among a mix of multiple products (e.g., level of complementarity) and the variations in information presentation (e.g., to which item is the discount attached?) (Xia and Bechwati 2021).

Bundling is a phenomenon applied by many, if not all, industries (Kinberg and Sudit 1979), and it is identified as being a common practice used as a strategic tool to gain competitive advantage (Lawless 1991). Sheng et al. (2007) refers to telecommunications industry and highlights that bundling strategy has sparked a war between several competitors such as American telecommunications company AT\&T, which had over than 3.5 million bundles subscribers at the end of the third quarter of year 2003, and its revenue from bundle addition increased to $\$ 521$ million, representing a 77\% increase in its turnover.

Vendors can employ two forms of bundling, pure or mix bundling (Guiltinan 1987). In the first one, pure bundling, products ${ }^{1}$ are available only in the bundle form, which means they cannot be purchased individually (Sheng et al. 2007). An example of this is the Netflix streaming service, in which subscribers access movies from any device (Ma and Mallik 2017). A mixed bundling strategy refers to selling products individually as well as in a bundle. This paper will focus in mix bundling due to three reasons. First, pure bundling is relatively rare in market. Second, in a few cases, pure bundling might be considered illegal when it involves separate products by a firm with market power and no plausible consumer benefits offset the potential damage to competition (Stremersch and Tellis 2002). An example of this is the case where Microsoft was accused of illegally tying the Internet Explorer web browser to the Windows operating system (Todd 2017). A third reason is explained by the fact that mixed bundling is incrementally superior over pure bundling (Andrews et al. 2009; Adams and Yellen 1976; Schmalensee 1984; Stremersch and Tellis 2002; Kopczewski et al. 2018).

Since the foundational studies of Stigler (1962) and Adams and Yellen (1976), economists have extensively studied the factors under which bundling is more profitable than separate sales (Kopczewski et al. 2018). Several key factors on the demand and supply sides are considered in bundling rationality. The transference of part of the consumer surplus associated with one bundle item to the other item, which may initially present a deficit in the consumer's assessment, and lately the bundle acquires a positive utility (Bakos and Brynjolfsson 1998; Stigler 1962; Adams and Yellen 1976; Guiltinan 1987; Schmalensee 1984), is among the most studied factors in bundling. A second rationality entails bundling as a segmentation tool (it depends on the customer map). Bundling of products is perhaps the most widely used tactic to apply discriminated prices, although its logic often goes unnoticed (Nagle 1984). Another approach relates to the firms' pricing and promoting of bundle (Venkatesh and Mahajan 1993). An alternative field of research is related to optimality of bundling (Dodds et al. 1991; Bakos and Brynjolfsson 1998; Guiltinan 1987).

However, most studies do not consider complementarity within bundle products assuming that those bundled components are independent; hence, such an assumption does not capture the impact of product complementarity (Chen et al. 2020), leading to inadequate bundling decisions to managers when defining sales strategy. In fact, some authors argue that a product evaluation can deteriorate if this product is presented in a 
price bundle and that this effect depends on the framing of price discounts in the bundle (Chen et al. 2020).

Therefore, the present study contribution is a deeper analysis of complementarity effects, together with other key factors, namely price and discount level, in bundles evaluations.

It is a matter of raising to light a number of biases in consumers' evaluations of bundling offers, since the effects bring natural questions to sellers: Is a bundling sale strategy advantageous when compared to the sale of individual products? Does the complementarity of bundle components affect consumers' preferences? How do price level and the discount of the bundle affect consumers' purchase intention? This paper aims to compare the preference that consumers have between individual products and bundles and to investigate certain factors, e.g., price level, discount level, and complementarity, that may affect consumers' preferences.

To address the mentioned questions, an empirical study was conducted with a Portuguese sample that was gathered by means of an online questionnaire divulged by a research market company named Netquest during August 2019 in Portugal. The sample was developed in order to represent the target population; therefore, the sample is representative. The respondents were 20 years old or more and were responsible for purchasing decisions. The questionnaire was distributed in all the municipalities of Portugal including the islands of the Azores and Madeira. Answers were collected from 127 municipalities, and 375 questionnaires were complete and used to analyze and conclude.

Based on the results of Likert-scale evaluations (to measure the attractiveness, quality, and purchase intention of different products), $t$-tests were conducted to search for significant differences in consumers' perceptions. The major findings are that preferences for individual products are higher in comparison to a bundle when the discount level assigned to a bundle is $0 \%$ or $20 \%$. However, preferences reverse on a discount level of $45 \%$ This result means that consumers only consider a valuable discount on a bundle offer when the discount is relatively high.

This paper is organized as follows. In Section 2, a review of the related literature is provided with the hypothesis formulation for the present research. Section 3 introduces the methodology applied and data used in the empirical analysis. Section 4 describes the empirical results obtained. Section 5 includes the discussion and managerial implications. In Section 6, conclusions are presented. Finally, Section 7 provides research limitations and future research directions.

\section{Theoretical Background and Hypothesis Formulation}

\subsection{Individual Products or Bundles}

Faced with a bundle, it is unclear whether maximisers focus on assessing the value of the individual products or on evaluating the bundle as a whole (Xia and Bechwati 2021). To understand which is more valuable by consumers, bundles or individual products is the first subject under research. This understanding is relevant, as several authors advocate distinct scenarios: bundling is widely implemented for information goods and online services because it can increase profit for companies (Ye et al. 2017); bundling is an effective strategy for companies to increase revenues (Honhon and Pan 2017); bundles generally are not preferred over separate products (Knutsson 2011).

A probabilistic approach was proposed (Venkatesh and Mahajan 1993) to optimize the price of a bundle of products that maximizes manufacturer profits. To obtain their results, the authors focus on a situation where the consumer decision-making process is a function of two dimensions of independent resources: the time available and the reservation price of the show. Their conclusion indicates that mixed bundling strategy is more profitable than the individual sale of each show.

The bundling advantage can have different roots and explanations. One of the most empirical research studies is related to customer's reservation price. The profitability of bundling sales stems from the decrease of variance of customers' valuations of the products (Ye et al. 2017). This implies that when a bundle is composed by two products in which 
consumer reservation prices for the two types of products are negatively correlated, the valuation for the bundle will be higher than the valuation of individual goods.

According to several authors (Dansby and Conrad 1984; Adams and Yellen 1976; Guiltinan 1987), the utility (value) of a bundle is equal to the sum of the value of the individual products that make up the bundle, the so-called additivity proposition. However, some authors mention that superadditivity can also happen. When products are complements, a consumer's reservation price for the bundle is superadditive (Venkatesh and Kamakura 2003). In this scenario, the consumer's preference for a bundle is higher than the sum of the individual product's preference. Alternatively, when the products are substitutes, a consumer's reservation price for the bundle would be subadditive in those for the components (Venkatesh and Kamakura 2003). For instance, when Walmart presents a bundle that combines two distinct brands of milk, the consumer's reservation price for one brand of milk declines, given that another substitute will be purchased (Chen et al. 2020).

The prospect theory was also used to explain the comparison between individual items and bundles (Harlam et al. 1995). The authors explain that according the theory, consumer utility functions are concave to earnings (products) and convex to losses (cost or price), and in addition, the loss function is more pronounced than gain function, so that losses cause more injury than gains cause benefit. Consequently, to the extent that consumers view separate products in a bundle as distinct benefits (gains) for a price (loss), they would be more likely to buy bundle products than they would be to purchase the products separately.

Bundle products are perceived as more popular than products offered individually; as such, the bundle highlights the salience of products, which has a positive effect on consumer's preferences (Chakravarti et al. 2002). Another author (Yadav 1995) mentioned the bundling superiority. His proposition states that the principle of price discrimination through the bundling is related to a strategy that mainly involves encouraging purchases of various items in groups of buyers who would normally buy only one of the two items, but not both.

Thereby, the first research hypothesis is:

Hypothesis 1 (H1). Bundles have a higher preference than individual products.

This hypothesis is divided in:

Hypothesis 1 (H1a). Bundles have a higher preference over individual products in what concerns quality.

Hypothesis 1 (H1b). Bundles have a higher preference over individual products in what concerns attractiveness.

Hypothesis 1 (H1c). Bundles have a higher preference over individual products in what concerns the purchasing intention.

To answer this research question, (Knutsson 2011), and (Gaeth et al. 1990) applied a similar method that implies comparing the valuations between bundles with the average of the individual products valuations (here considered aggregate products) that compose the bundle.

\subsection{Complementarity}

Despite being eloquent, the economic approach when applied in isolation would be inadequate for the bundling study because it neglects the subjective nature of the consumer's decision-making process when evaluating bundles of different products (Harlam et al. 1995). It may also be added that the economic approach almost completely ignores the relation between the products making up the bundle and which possible factors affect consumer valuation. 
Complementarity relates to the type of relation among individual products. Complementary bundles refer to those in which the products included in it work as a system (e.g., a computer and a printer) (Sheng et al. 2007). On the other hand, noncomplementary or unrelated bundles refer to the set of products included in the bundle that are not functionally related (e.g., a television and a bicycle). The great majority of the bundling studies consider complementarity as having two dimensions: complementary bundles and noncomplementary bundles. This work will follow the same logic.

When the bundle has a high integration between products, the greater its added value (Stremersch and Tellis 2002). Previous research has showed that consumers may associate the purchase of a bundle with the reduced risk it promotes when compared to buying individual products due to the functional compatibility (Harris and Blair 2006). This latter study concluded that by increasing the salience of the complementarity risk between individual products, consumers will tend to buy the bundle.

(Lawless 1991) advocates that bundling encompasses the grouping of related (complementary) products into a unified offer. Consumers may consider complementary bundles as something that creates synergies due to the simplification of the buying process (Sharpe and Staelin 2010). This implies that consumers will be able to value the bundle more than the sum of the value of individual products and therefore will have a positive incentive to buy the bundle (Venkatesh and Kamakura 2003), corresponding again to the superadditive and subadditive factors mentioned before.

Alternative reasons can explain the higher preference of complementary bundles over noncomplementary bundles: for instance, search costs that the consumer will save, assembly costs (e.g., sale and installation of air conditioning) (Guiltinan 1987; Harris and Blair 2006), transaction costs, information costs, the satisfaction of buying various products under the name of a well-known brand, the ease of obtaining after-sales support from a single company, or the increased performance of bundle products designed to be integrated (Lawless 1991). A tool that will help to better understand consumer behaviour is the canvas customer and value map. ${ }^{2}$ The identification of customer jobs, pains, and gains will help to improve the value offer to consumers, helping like this in a more effective communication.

Then, the second research hypothesis is as follows:

Hypothesis 2 (H2). Complementarity bundles have a higher preference than noncomplementary bundles.

This hypothesis is divided in:

Hypothesis 2 (H2a). Bundles formed by complementary products are preferred over bundles formed by non-complementary products in what concerns quality.

Hypothesis $2 \mathbf{( H 2 b ) . ~ B u n d l e s ~ f o r m e d ~ b y ~ c o m p l e m e n t a r y ~ p r o d u c t s ~ a r e ~ p r e f e r r e d ~ o v e r ~ b u n d l e s ~}$ formed by non-complementary products in what concerns attractiveness.

Hypothesis 2 (H2c). Bundles formed by complementary products are preferred over bundles formed by non-complementary products in what concerns the purchasing intention.

\subsection{Price Level}

The price level of a product is obviously a relevant variable in the consumer buying decision. Harlam et al. (1995) focused their research to understand whether a bundle composed of products whose prices are similar results in a greater purchase intention than in the case where a bundle is composed of products whose prices are not similar. According to the author's proposition, if the individual product's prices included in the bundle are very disparate, then the bundle may be perceived essentially as a purchasing in which the second product is "free" (freebee), and as such, unimportant (e.g., a computer and a mouse). Thus, according to the same authors, the price of the second product will be largely ignored, but if on the other hand, the price of individual products is similar, the bundle price will be considered "real" (e.g., washing and dryer machine). In this case, 
consumers will consider both prices relevant, actual, and fair. Therefore, according to this preposition, bundles composed of items whose prices are similar will present a superior evaluation to the bundles with items that have disparate prices. However, the research of Harlam et al. (1995) did not find significant evidence to supporting this hypothesis.

As such, the present study proposes research with a different perspective regarding the bundle's price level. This research is focused on an analysis of the bundle's final price level and not the price difference of each individual product included in the bundle. In the present work, two price levels are considered: high versus low price. High price does not mean that the bundle is expensive or over-priced but rather that the bundle is composed with products of a superior category or range, so the price is higher as well. While the low-price bundle refers to a bundle composed of products of lower rank or category, then its price will be lower. The third research hypothesis is as follows:

Hypothesis 3 (H3). The bundle price level will interact with consumer preferences.

This hypothesis is divided in:

Hypothesis 3 (H3a). The bundles' price level interacts with the consumers 'preferences in what concerns quality.

Hypothesis $\mathbf{3} \mathbf{( H 3 b )}$. The bundles' price level interacts with the consumers 'preferences in what concerns attractiveness.

Hypothesis $3 \mathbf{~ ( H 3 c ) . ~ T h e ~ b u n d l e s ' ~ p r i c e ~ l e v e l ~ i n t e r a c t s ~ w i t h ~ t h e ~ c o n s u m e r s ~ ' p r e f e r e n c e s ~ i n ~ w h a t ~}$ concerns the purchasing intention.

\subsection{Discount Level}

When the valuation of bundles is compared with individual products (Knutsson 2011), the conclusion indicates that in the absence of a monetary discount, the bundle always has a lower valuation than individual products. Hence, the author asks why the bundles proliferated in the market if their valuation is not superior, which may seem counterintuitive. Why do companies adopt a bundling strategy if they do not increase the attractiveness or sales of their products? The justification for adopting this strategy may be related to the attribution of discounts to bundles (Knutsson 2011; Xia and Bechwati 2021). Then, it is pertinent to see if there is in fact a superior valuation for discounted bundles when compared to individual products without discount. As done by this last author, bundles will be evaluated with a discount, while the individual products will be evaluated without discount, because this is the most frequent scenario in the market. When consumers have plans to buy a certain type of product, this is the choice consumers face in stores (Knutsson 2011).

From the company's point of view, it is important to stimulate consumers through incentives (Darke and Chung 2005). For that, once again, it is mandatory to have a customer characterization (Customer Map). Financial incentives that are presented as a monetary benefit may induce customers to perceive added value in a product, and as such, the purchasing probability may increase (Andrews et al. 2009).

The justification for the consumer to select a discounted bundle even when it does not value both products can be explained by the conceptualization given by Foubert and Gijsbrechts (2007) or by a gain identified by the consumer. If the seller identifies this potential gain from the customer perspective, it can be exploited from the seller side. According to these authors (Foubert and Gijsbrechts 2007) when the total purchase quantity that a consumer needs is less than the quantity requirement established by the bundle to receive the promotional price, it is expected that the rational consumer will avoid any reaction related to that discount. This is because the bundle discount has no justification for such a purchase. However, the authors argue that consumers may still respond to bundle discount as a result of positive and/or negative psychological effects. The authors call this phenomenon the "discount communication effect". Moreover, the typical bundling 
strategy is to offer the bundle at a discount to act as an incentive for consumers to select the bundle rather than individual products (Herrmann et al. 1997).

Other authors (Stremersch and Tellis 2002) argue that in the case of using the price bundling, which means using different quantities of the same product (e.g., a pack of six beers), a discount is required to attract the consumer. In contrast, in the case of using product bundling, which means a bundle composed of distinct products (e.g., computer and a printer), which is the concept under analysis in the present paper, no discount is required to attract consumers. Their explanation indicates that in the price bundling case, once the products are not integrated, because they are the same product but in different quantities, the bundle reservation price is equal to the sum of the individual products' prices, and the bundle alone does not create added value to consumers, so a discount must be offered to motivate at least some consumers to buy the bundle. On the other hand, product bundling, as it is an integration of two or more distinct products, offers added value at least to some consumers (Stremersch and Tellis 2002). This notion is relevant, since it contradicts the idea that a discount is needed for a bundle to be more valuable than individual products. Price appears to play two opposite roles in the consumers' purchasing decisions-allocative and informational (Herrmann et al. 1997). A higher price decreases consumer utility, because they must pay more for the product, and a higher price may induce higher quality perceptions, increasing the consumers' utility. One of the functions of price on branding is to inform the consumers about the perceived quality they must expect, taking into account the price.

Since the first research hypothesis already addresses the study of bundles without discount, at this point, it is proposed to approach the bundles at a discount and compare its evaluation with individual products without discount. The fourth research hypothesis is as follows:

Hypothesis 4 (H4). Discounted bundles have a preference over individual products without discount.

This hypothesis is divided in:

Hypothesis $4 \mathbf{( H 4 a ) . ~ B u n d l e s ~ w i t h ~ a ~ d i s c o u n t ~ a r e ~ p r e f e r r e d ~ o v e r ~ i n d i v i d u a l ~ p r o d u c t s ~ w i t h o u t ~ a ~}$ discount in what concerns quality.

Hypothesis $4 \mathbf{( H 4 b ) . ~ B u n d l e s ~ w i t h ~ a ~ d i s c o u n t ~ a r e ~ p r e f e r r e d ~ o v e r ~ i n d i v i d u a l ~ p r o d u c t s ~ w i t h o u t ~ a ~}$ discount in what concerns attractiveness.

Hypothesis $4 \mathbf{( H 4 c )}$. Bundles with a discount are preferred over individual products without a discount in what concerns the purchasing intention.

It is important not only to comprehend the discount effect, but likewise the effect of different discount levels. The possibility of significant discounts gives rise to quality suspicions and may negatively affect the assessment of the bundle, since price is a strong indicator of quality. That is, a lower price indicates a lower quality, and a higher price indicates higher quality (Rao and Monroe 1989). If the discount is considered to be excessive by the consumer, it may raise quality doubts (Bitta et al. 1981; Knutsson 2011). This is, the discount may cause an unintended effect, and the bundle may be evaluated as a lower quality offer (Sheng et al. 2007). With the aim of verifying if in fact a significant increase in the discount level negatively affects the consumer assessment, this work will address different levels of discount allocated to bundles. Two discount levels were assigned to bundles: $20 \%$ and $45 \%$. The $20 \%$ represents an intermediate level of discount, and as there is no value to indicate from which level the effect of the discount may manifest as a negative consequences, it will be considered the same level as the research of Knutsson (2011), which is a $45 \%$ discount.

The three factors under research are described in the conceptual model: complementarity, price level, and discount level Factors such as consumer assessment will be reflected 
by the preference construct through the scales of quality, attractiveness, and purchasing intention. Figure 1 represents the expected influences between quality, attractivity and purchasing decision (independent variables) and the consumers' preferences (dependent variable). It is also highlighted the fact that these influences are expected to be moderated by complementarity, price level and the discount level.

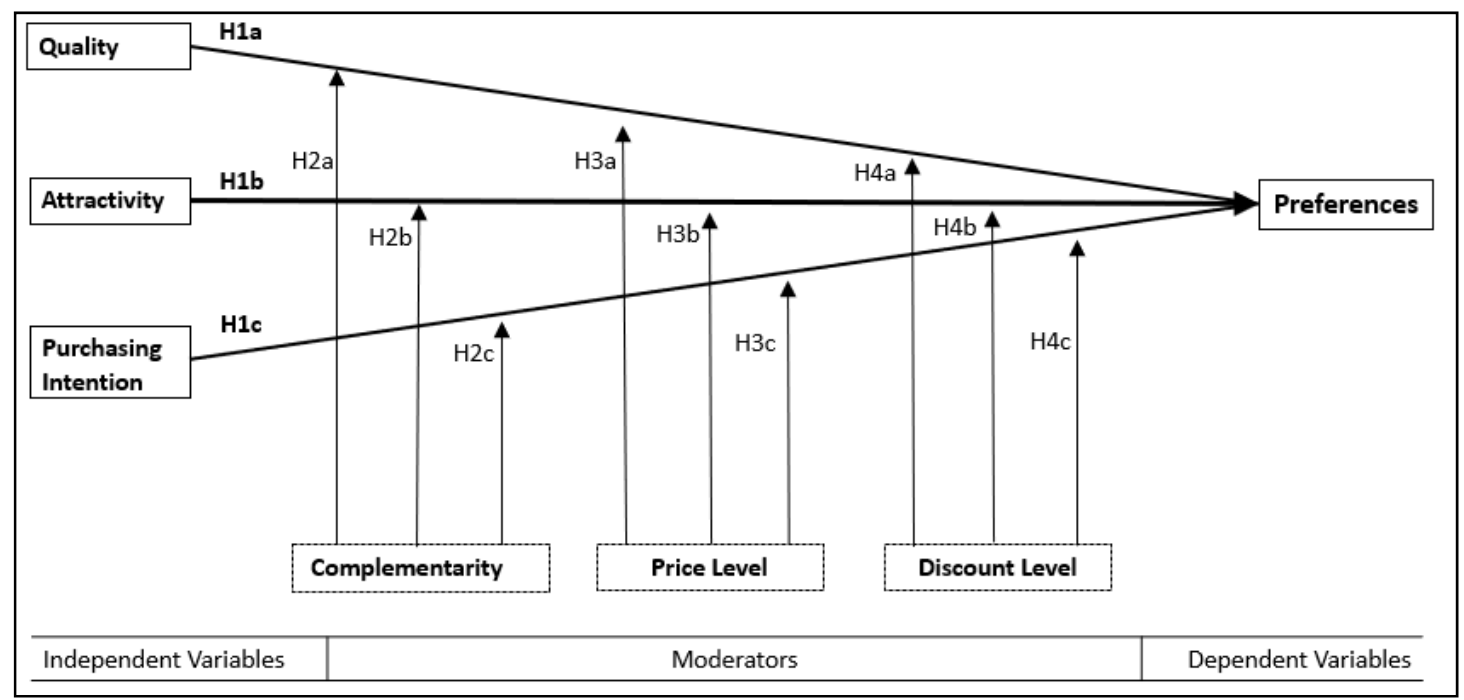

Figure 1. Conceptual model.

\section{Materials and Methods}

\subsection{Data Analysis}

This work employs a collection and analysis of empirical and quantifiable data through the performing of one online survey to consumers.

The study population refers to the national territory of Portugal. Respondents would have to be decision-makers of the purchase process and be at least 20 years old.

Since the variable, discount level, includes two dimensions, $20 \%$ and $45 \%$, attributed to a bundle, it was necessary to elaborate two variants of the questionnaire in the section that includes the evaluations of those and one variant that includes no discount. In total, 375 individuals with valid answers were collected, where the number of respondents was subdivided by three groups with the same size, that is, 125 respondents for each discount level. The sample is composed by $49 \%$ of males and $51 \%$ of females; the range of age varied from 20 to 81 years old, and the average is 37 years old; the majority $47.7 \%$ have a bachelor's degree; $73 \%$ of the sample have a job; $46.1 \%$ have a monthly household net income between $€ 1001$ and $€ 2000$; on average, the household is composed of 3 persons.

\subsection{Questionnaire Structure}

The questionnaire includes six groups. (1) The first group includes questions about gender and age. (2) The second group includes an evaluation of three individual high price products. (3) The third group consists of sociodemographic data. (4) The fourth group includes a valuation of the three individual low-price products. The intention of introducing sociodemographic questions between the evaluation of individual highprice products and low-price products is to reduce the possible comparative effect that subjects can process. This is because both high and low-price products are the same, only varying the product category, thus varying the characteristics and price. (5) Two distraction questions were added: one about favourite vacation destination and one about favourite hobby. (6) The evaluations of the bundles. The previous distraction questions have the function of separating the evaluations between the individual products and bundles so that consumer does not allow himself to be influenced between the two scenarios, since 
bundles are composed of the same individual products, high and low-price, which are previously evaluated.

The sixth part concerning the bundle's evaluation is formed by three variants due to the urgency of studying the bundles without discount and the two different discount levels assigned to the bundles: $20 \%$ and $45 \%$. Then, the respondents could randomly be asked to respond to a bundle discount level of $0 \%, 20 \%$, or $45 \%$.

Individual products and bundles were presented with photos and short specifications alongside with pricing information, similar to the methods from previous research (Knutsson 2011). Only four characteristics per product were described, and these same characteristics varied according to product or bundle category (high or low price).

\subsection{Scales}

With the purpose of measuring the consumer's evaluations for individual products and bundles, three scales related to the preference construct were applied (Knutsson 2011). The scales are quality, attractiveness, and purchase intention. All scales were measured using the seven-point Likert scale according to Table 1.

Table 1. Scales.

\begin{tabular}{ccc}
\hline Scales & \multicolumn{2}{c}{ Level of Scales } \\
\hline Quality & 1-Low Quality & 7-High Quality \\
Attractivity & 1-Low Attractivity & 7-High Attractivity \\
Purchasing Intention & 1-Nothing Likely & 7-Very Likely \\
\hline
\end{tabular}

The three scales, quality, attractiveness, and purchase intention, capture three different aspects of construct preference. Perceived quality is strongly related and is a precedent of preferences (Rust et al. 1999). Preferences are usually measured through the scale of the purchase intention (Gaeth et al. 1990; Harlam et al. 1995). However, preferences are not always translated into purchase, since a consumer may prefer product A instead of product $B$ and still not acquire any of them. Other scales should be added to the construct preferences so that their measurement is more realistic. Attractiveness is likewise a factor capable of measuring preference.

\subsection{Selection of Products and Prices}

This work is restricted to two-item bundles once they are most common in the marketplace, and it simplifies the respondent's review tasks.

To analyze all the factors included in this work-complementarity, discount level, and price level-six products were selected: three high-price products and three low-price products. With the purpose of creating the bundles, these same individual products were used (Table 2). The value of high and low-price products was defined considering the average market prices in Portugal for these same products with a 30\% increase in price for the high-price scenario and a 30\% decrease for the low-price scenario.

Table 2. Selection of product and bundles.

\begin{tabular}{|c|c|c|c|c|c|c|c|c|}
\hline $\begin{array}{l}\text { Price Level } \\
\text { Bundle Type }\end{array}$ & \multicolumn{4}{|c|}{ High Price } & \multicolumn{4}{|c|}{ Low Price } \\
\hline \multirow{3}{*}{ Complementary } & \multirow{3}{*}{ (a) } & Laptop & & Printer & \multirow{3}{*}{ (c) } & \multicolumn{2}{|l|}{ Laptop } & \multirow{3}{*}{$\begin{array}{l}\text { Printer } \\
\text { Low Price } \\
€ 46 \\
€ 501\end{array}$} \\
\hline & & High Price & + & High Price & & Low Price & + & \\
\hline & & Bundle & $=$ & $€ 930$ & & Bundle & $=$ & \\
\hline \multirow{4}{*}{$\begin{array}{c}\text { Non } \\
\text { Complementary }\end{array}$} & \multirow{4}{*}{ (b) } & Laptop & & Coffee Machine & \multirow{4}{*}{ (d) } & LaptopLow & & Coffee Machine \\
\hline & & High Price & + & High Price & & Price & + & Low Price \\
\hline & & $€ 845$ & & $€ 83$ & & $€ 455$ & & $€ 45$ \\
\hline & & Bundle & $=$ & $€ 928$ & & Bundle & $=$ & $€ 500$ \\
\hline
\end{tabular}




\section{Empirical Results}

\subsection{Evaluation of Individual Products and Bundles}

The main contribution of the first research hypothesis is the comparison between bundle's preferences and individual products. Bundle's valuations are compared to aggregate valuations of individual products, which means the average of individual product.

Figure 2 presents the overall valuations of both aggregate products and bundles. It can be noticed that bundles do not present a superior result than individual products. One-sample $t$-test (Table 3 ) shows that the difference for quality scale is not statistically significant. In the case of attractiveness and purchase intention, valuations have differences that are statistically significant. Contrary to what $\mathrm{H} 1$ advocates, bundles do not have a higher preference than aggregate products, and it is not possible to confirm H1. These results are aligned with the conclusion of (Shaddy and Fishbach 2016), who found that consumers offer a lower willingness to pay for items acquired as bundles compared to the same items purchased separately.

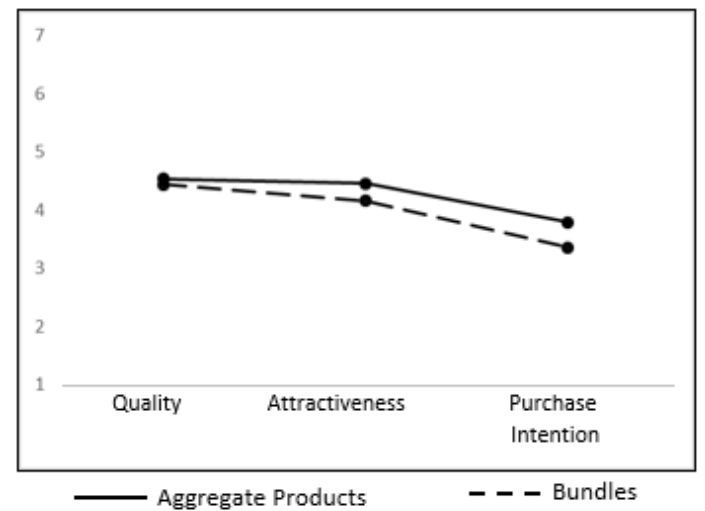

Figure 2. Overall valuations for aggregate products and bundles.

Having analysed the overall valuations, it is pertinent to proceed with an isolated analysis of each of the four bundles with the corresponding aggregate products. Figure 3 shows the case of complementary bundles, both high and low price in the three scales, in which aggregate products have a higher valuation, although this is not statistically significant. In the case of noncomplementary bundles, their valuation was less positive than aggregate products both in high and low-price scenarios for the three scales.

Table 3. One-sample $t$-test for aggregate products and bundles.

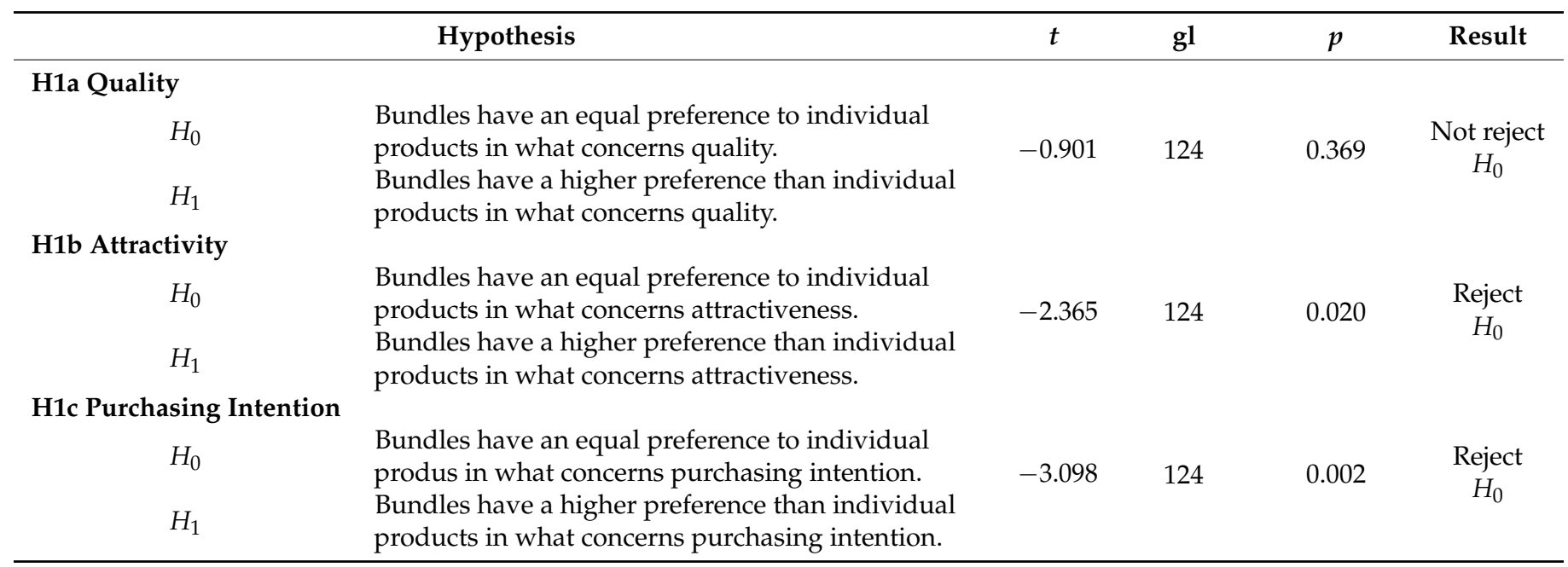




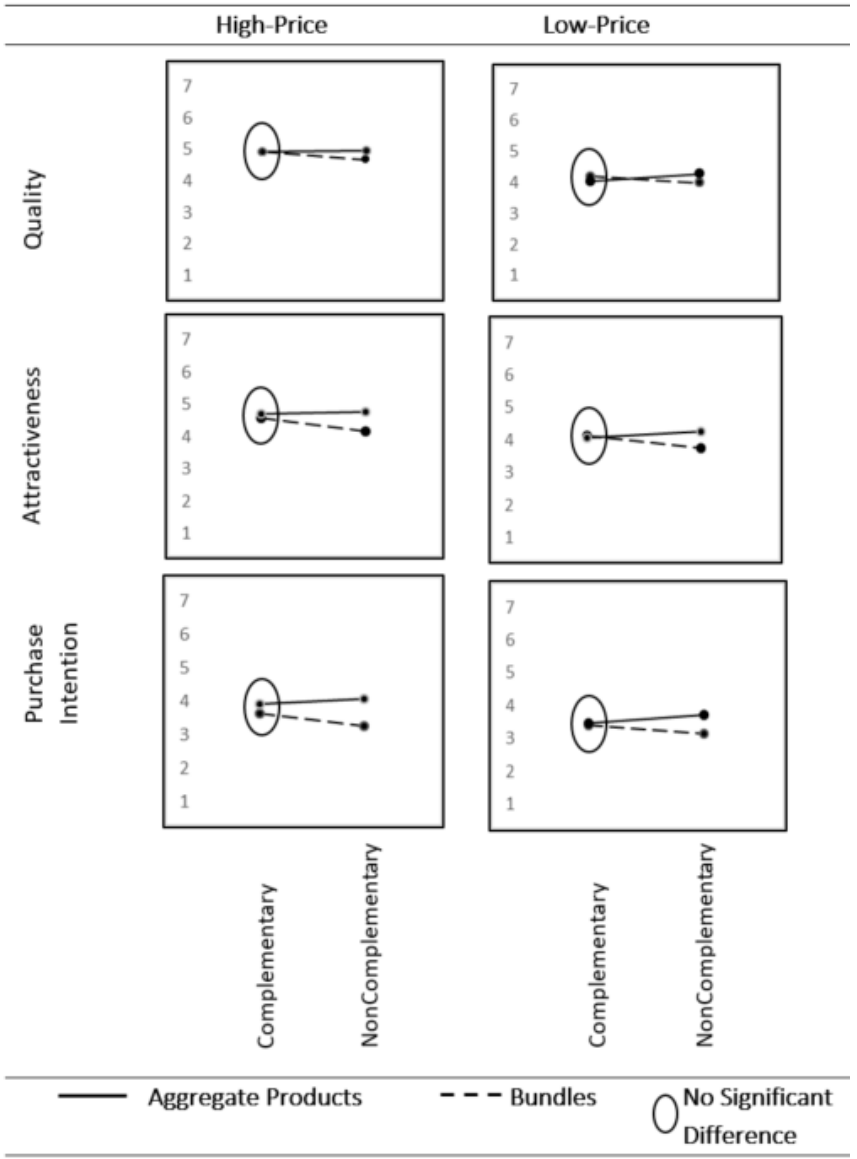

Figure 3. Isolated analysis for aggregate products and bundles $0 \%$ discount.

The results show that bundles often exhibit a lower rating than individual products. The results are consistent with Knutsson (2011). However, they contradict the proposition of Goldberg et al. (1984) that the value of the bundles corresponds to the average of the individual items. They also contradict the conclusions of Harlam et al. (1995) and Venkatesh and Mahajan (1993), which concluded that bundles present a superior evaluation than individual products. None of the bundles had a higher preference over individual products; however, in the case of the complementary bundles, the valuation differences are not statistically significant, and in the case of noncomplementary bundles, their valuation is always lower than that of individual products

\subsection{Complementarity}

The second research hypothesis is related to complementary bundles and noncomplementary bundles. Figure 4 shows that complementary bundles present a higher valuation. Paired-sample $t$-tests have shown that valuations are statistically significant. With these results, $\mathrm{H} 2$ is confirmed.

Table 4 presents a summary of the paired sample $t$-test for complementarity.

The results presented in Table 4 confirm the proposition of Lawless (1991) that a successful bundle should present some additional value such as the increased performance of bundle products designed to be integrated. Another assumption is also confirmed by, Telser (1979) that complementarity between products is a source of strategic advantage. Similarly, the conclusions of Harlam et al. (1995) are corroborated, which says that a bundle composed of complementary items will result in higher purchase intention. Yet, the conclusions of Gaeth et al. (1990) are confirmed, which showed that the separate evaluations of the two products are averaged to form an overall evaluation for the bundle, but in the case of complementarity, it positively affects the bundle's valuation. 


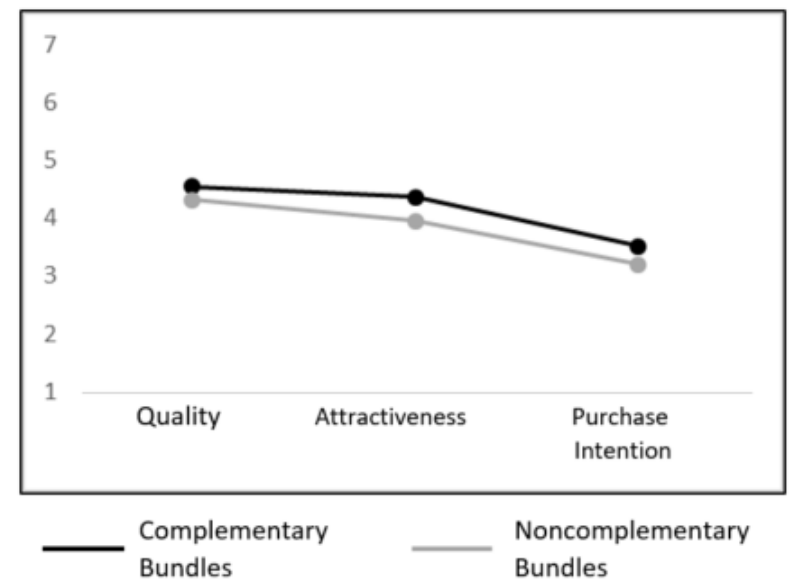

Figure 4. Overall evaluations for complementary and noncomplementary bundles.

Table 4. Paired-sample $t$-test for complementarity.

\begin{tabular}{|c|c|c|c|c|c|}
\hline & Hypothesis & $t$ & gl & $p$ & Result \\
\hline \multicolumn{6}{|l|}{ H2a Quality } \\
\hline$H_{1}$ & $\begin{array}{l}\text { Complementarity bundles have an equal preference } \\
\text { to noncomplementary bundles in what } \\
\text { concerns quality. } \\
\text { Complementarity bundles have a higher preference } \\
\text { than noncomplementary bundles in what } \\
\text { concerns quality. }\end{array}$ & 4.074 & 124 & 0.000 & $\begin{array}{c}\text { Reject } \\
H_{0}\end{array}$ \\
\hline \multicolumn{6}{|c|}{ - } \\
\hline$H_{1}$ & $\begin{array}{l}\text { Complementarity bundles have an equal preference } \\
\text { to noncomplementary bundles in what } \\
\text { concerns attractiveness. } \\
\text { Complementarity bundles have a higher preference } \\
\text { than noncomplementary bundles in } \\
\text { what concerns attractiveness. }\end{array}$ & 5.850 & 124 & 0.000 & $\begin{array}{c}\text { Reject } \\
H_{0}\end{array}$ \\
\hline \multicolumn{6}{|c|}{ H2c Purchasing Intention } \\
\hline$H_{1}$ & $\begin{array}{l}\text { Complementarity bundles have an equal preference } \\
\text { to noncomplementary bundles in what concerns } \\
\text { purchasing intention. } \\
\text { Complementarity bundles have a higher preference } \\
\text { than noncomplementary bundles in what concerns } \\
\text { purchasing intention. }\end{array}$ & 4.734 & 124 & 0.000 & $\begin{array}{c}\text { Reject } \\
H_{0}\end{array}$ \\
\hline
\end{tabular}

\subsection{Price Level Effects}

Research hypothesis $\mathrm{H} 3$ relates bundle price level interaction with consumer preferences. Figure 5 shows the overall valuation of high and low-price bundles. It is possible to confirm that high-price bundles show a higher valuation. A paired sample $t$-test (Table 5) demonstrated that differences are statistically significant for quality and attractiveness scale; however, in the purchase intention, the differences are not statistically significant.

For purchase intention scale, it is confirmed that attractiveness is not necessarily synonymous with purchase, because the attractiveness scale is greater than the purchase intention, and it is also noticed that the respondents considered the respective prices at the time of purchase decision, because high-price products are considered to have superior quality are more attractive, but they do not attract a greater purchase intention. This finding confirms that respondents make economic considerations at the time of purchase. Based on the results, $\mathrm{H} 3$ is partially corroborated, as the price level has affected consumer preferences for at least two scales: quality and attractiveness. Regarding quality, the results show that the difference is not statistically significant. 


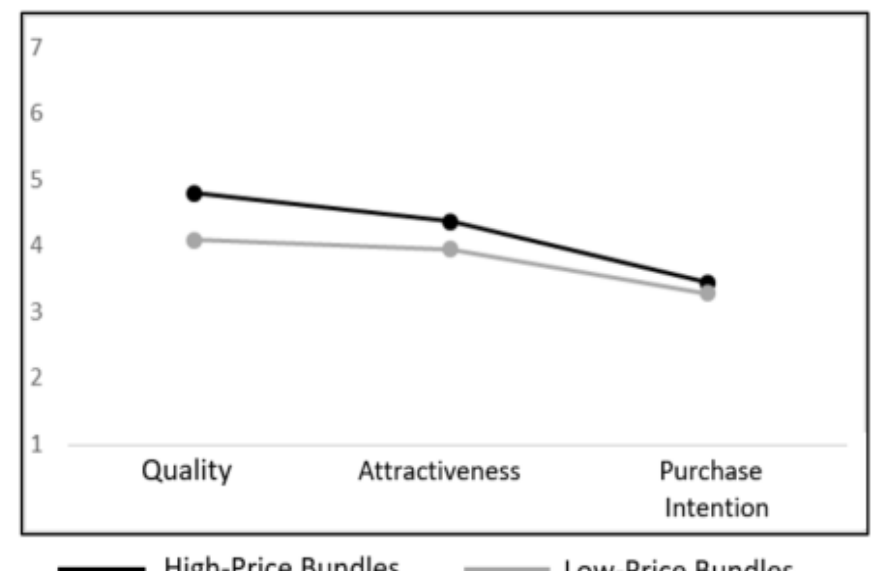

Figure 5. Overall evaluations for high and low-price bundles.

Table 5. Paired-sample $t$-test for price level.

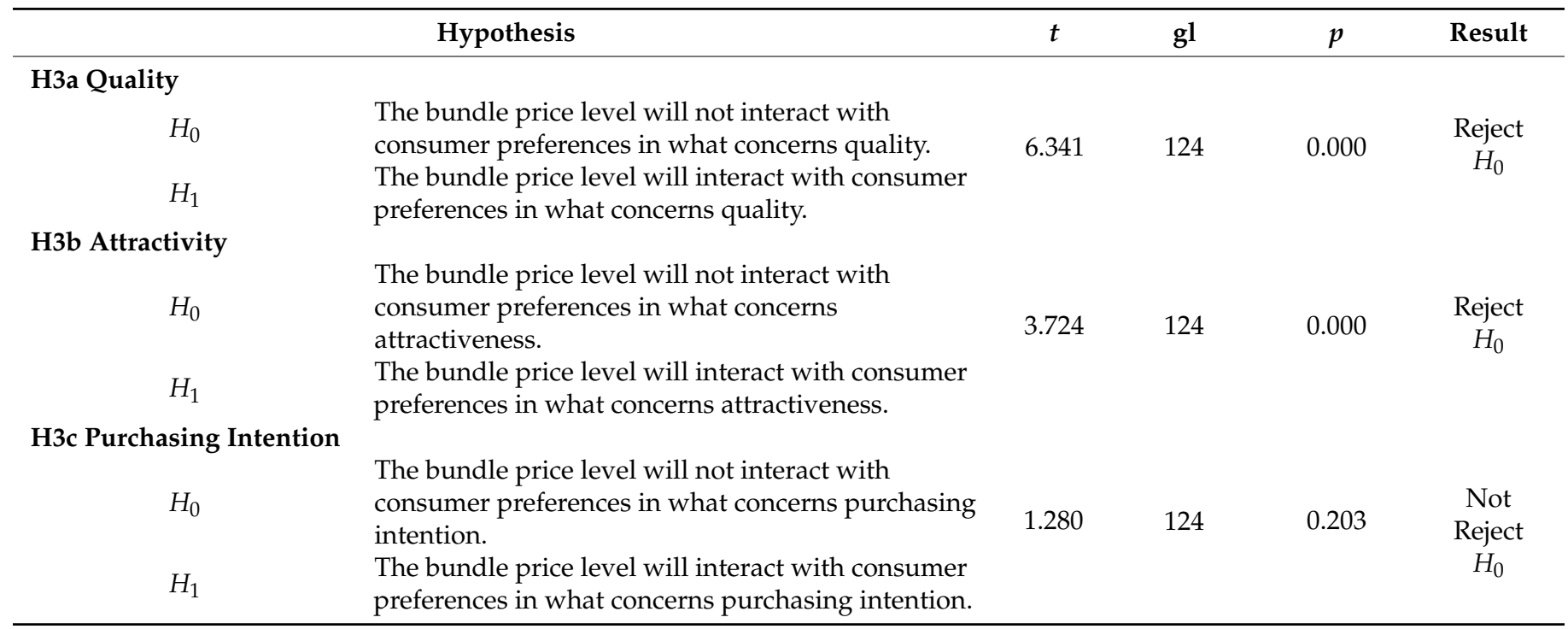

\subsection{Discount Level Effects}

In $\mathrm{H} 1$, it was verified that bundles do not present a higher preference than individual products. Thereby, the question remains: why are bundle sales so widespread in the market? Or why do companies adopt such a strategy? One justification might be related to the presentation of bundles at a discount. This is the reason behind H4: "Discounted bundles have a higher preference than individual products". For analysis purposes of this hypothesis, discount levels were assigned to bundles: $20 \%$ and $45 \%$. The valuation of discounted bundles is compared to the average of the aggregated products, without discount, that make up the bundle.

Figure 6 shows the results of overall evaluations for aggregate products and bundles with $20 \%$ and $45 \%$ discount. It is verified that even with a $20 \%$ discount, bundles present a lower overall evaluation than aggregated products. However, the differences are just statistically significant for quality scale. Analysing the bundles with $45 \%$ discount, it is possible to identify that bundles present a higher evaluation than aggregate products. Differences are statistically significant in the three scales. So, when a $45 \%$ discount is assigned to bundles, they have a higher preference than individual products. 


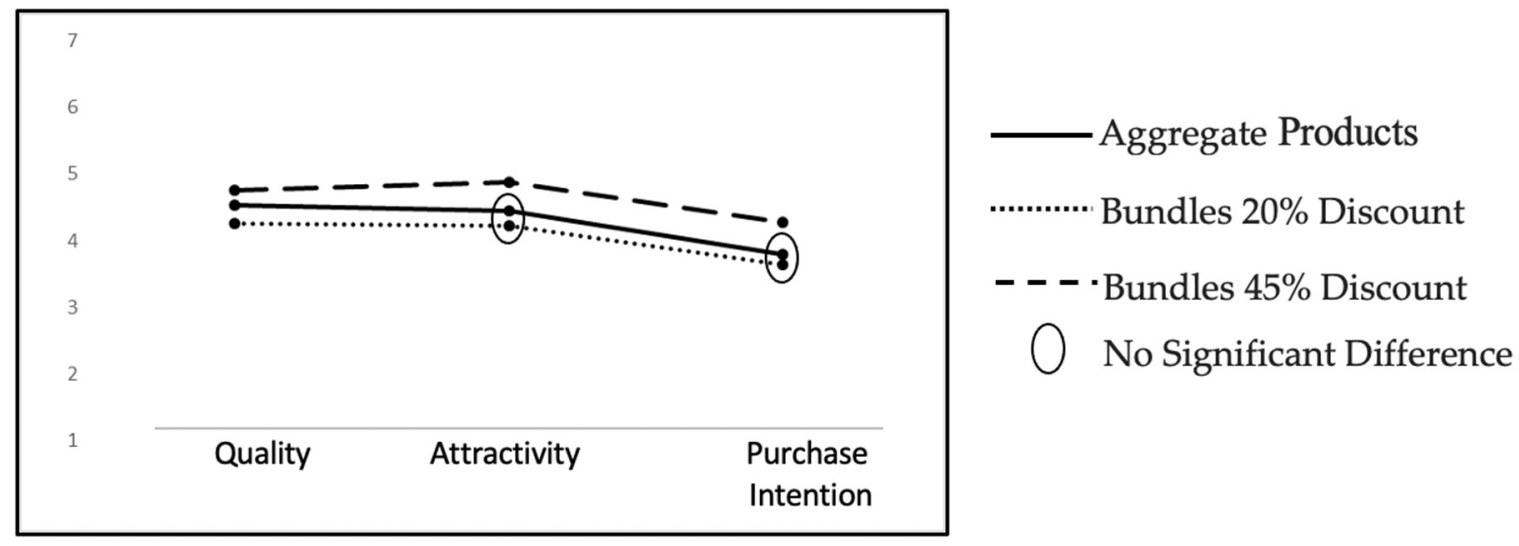

Figure 6. Overall valuations for aggregate products and bundles with $20 \%$ discount.

Nevertheless, as done in H1, a more isolated analysis is desirable, observing each of the four bundles with the corresponding aggregate products. In Figure 7a, regarding bundles with $20 \%$ discount level, it can be observed that complementary bundles of high price have a superior valuation than aggregated products in the three scales. Regarding complementary bundles of low-price, the valuation does not have a statistically significant difference for any scale. On the other hand, in the analysis of noncomplementary bundles, their valuation is lower than the aggregated products in all three scales and in both scenarios, the high and low price. Thus, with respect to the $20 \%$ discount level, it can be concluded that it is only advantageous to attribute such monetary incentive to complementary bundles of high price.

Examining now the $45 \%$ discount level, Figure $7 \mathrm{~b}$ shows that there is a superior evaluation of the complementary bundles in the three scales and in both high and lowprice scenarios. On the other hand, in the case of noncomplementary bundles and in both price scenarios, the differences are not statistically significant. Thus, the results indicate that even when a $45 \%$ discount is attributed to bundles, the effect of this price reduction give a higher evaluation to complementary bundles but is not enough for making the noncomplementary bundles valuation higher than individual products. It is concluded that with a $45 \%$ discount scenario, it is merely beneficial to attribute this discount if the bundles are considered complementary.

After analyzing the discount levels with isolated analysis, it can be concluded that $\mathrm{H} 4$ is partially confirmed-that is, bundles have a higher preference than individual products when the bundle discount is $45 \%$; contrarily, when the discount is $20 \%$, their evaluations remain lower.

These results contradict the conclusions of Knutsson (2011). The empirical evidence of this author was that complementary bundles, regardless of the discount level, were never rated higher than individual products, but in the present paper, when a $20 \%$ discount is assigned to a complementary bundle of high price, its valuation is higher than individual products, and with $45 \%$ discount, complementary bundles at both price levels surpass an individual product's valuation.

Moreover, the results refute the preposition of Stremersch and Tellis (2002), which argue that it is not necessary to assign discounts on complementary bundles to attract the consumer. The evidence also contests the idea advocated by Lawless (1991), that companies should charge a premium price for complementary bundles. It was found in the present study, and according to the results obtained, that if the complementary bundle does not present any discount, it does not reach the valuation of the individual product evaluations. A possible justification may be related to the fact that there are currently more alternatives and variety of products and the consumer is not so limited to a small number of suppliers. 


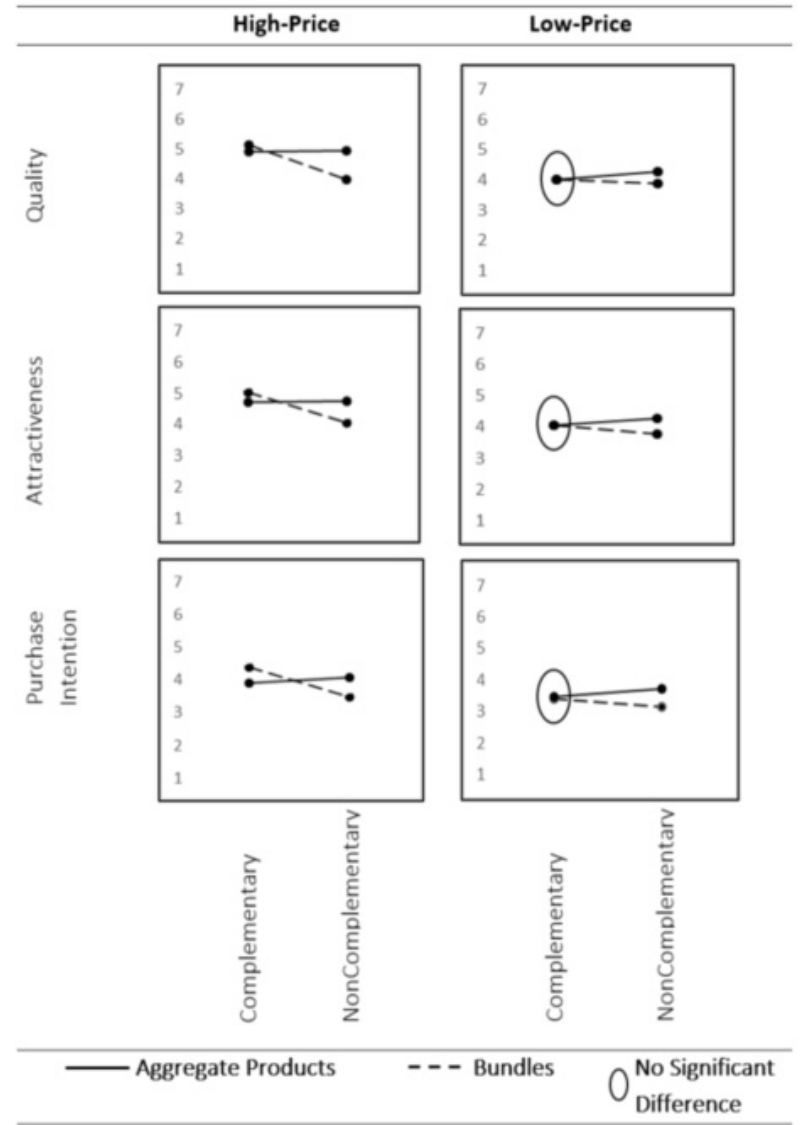

(a)

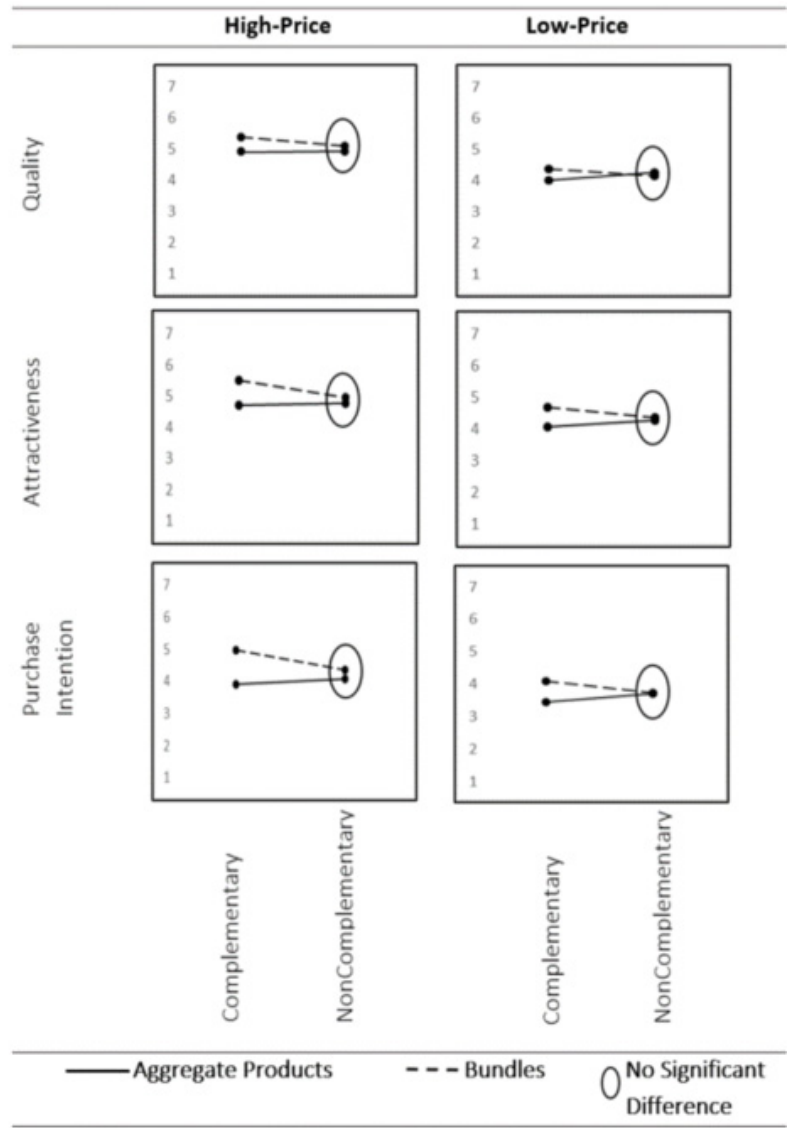

(b)

Figure 7. (a) Isolated analysis for aggregate products and bundles $20 \%$ discount; (b) isolated analysis for aggregate products and bundles $45 \%$ discount.

The results are consistent with Herrmann et al. (1997), which advocate that the typical strategy of bundling is to offer a discounted bundle to act as an incentive for consumers to opt for the latter rather than individual products. Additionally, we found evidence corresponding with the study of Derdenger and Kumar (2012), in which the authors show that consumers value individual products more than bundles; as such, a discount is required for the bundle to encourage purchase.

\section{Discussion and Managerial Implications}

\subsection{Discussion}

Bundling is so widespread in the market that it is usually a strategy not perceived by the various players, being that consumers often acquire goods or services that include more than one item in a single package.

Many authors argue that bundling is often used as a way to increase sales, and the proposition is that they do so because they are valued by consumers (Drumwright 1992; Yadav 1994; Chakravarti et al. 2002; Gaeth et al. 1990). However, that assumption was not confirmed in this study.

The results presented in this paper lead to relevant information when designing the values and customer map. If the bundle is not perceived by the customer as a gain, the seller shall not identify it as a gain creator. When comparing the preferences of two products sold individually, with the same two products sold in bundle format, the individual products obtained a higher overall preference. Then, these findings refute the conclusion of Gandal et al. (2018) which have shown that the correlation of consumer preferences over the components in the bundle presents higher profitable than individual products, refuting 
also the study of Chiambaretto and Dumez (2012) and Kübler et al. (2020) in which bundling is a promising strategy for many firms, especially when they have a large product portfolio. Furthermore, the findings show that when analysed on a case-by-case basis, the complementary bundles, both high and low price, presented a similar evaluation to individual products, while the evaluation of noncomplementary bundles was always lower. Therefore, it is concluded that bundles do not present a superior evaluation than individual products. This conclusion is crucial for the definition of marketing and communication strategies, (e.g., to be considered when developing a business model canvas).

The empirical study also demonstrates that all the complementary bundles have a higher preference over noncomplementary bundles, corroborating the positive effect of complementarity in the bundles evaluation and also the proposition of Lawless (1991) that a successful bundle should present some additional value, such as the increased performance of bundle products designed to integrate the bundle. When bundles present an integration between products that compose it, the greater its added value Stremersch and Tellis (2002). Thus, it can be considered that complementarity between products is a source of strategic advantage (Telser 1979). Once again, this result is relevant for the communication strategy: a bundle is perceived as a gain by the consumer when the products are complementary.

The empirical study also shows that high-price bundles, when compared with the low-price bundles, present a superior valuation, in the scale of quality and attractiveness, whereas in the scale of purchase intention, the results were similar. These results indicate that consumers make economic considerations through the buying process; that is, even when they consider a product of higher quality and more attractive, the purchase intention is lower because of the high price.

Since bundles did not have a higher preference than individual products, as confirmed in the first investigation point, the justification for bundle's dissemination in the market remains to be identified. The most apparent and frequently pointed reason in the market is related to the attribution of monetary discounts. As such, bundles were discounted, and their ratings were compared to individual products without discount. Two levels of discount were defined: $20 \%$ and $45 \%$.

Concerning the assessment of the bundles with a $20 \%$ discount, their overall valuation is inferior to the individual products. However, some caveats were found. The isolated analysis of each bundle showed that with a $20 \%$ discount, the complementary bundles of high price have a superior preference over individual products in the three scales. While for the valuations of complementary bundles of low price, its valuation is similar when compared to individual product evaluations. On the other hand, noncomplementary bundles present lower valuations over individual products at both price levels and on the three scales, which suggests that a $20 \%$ discount level is only effective for complementary bundles of high price.

Regarding the $45 \%$ discount level analysis, the results are different. Bundles with a $45 \%$ discount have a higher overall valuation over individual products. However, the isolated analysis reveals some underlying effects. Complementary bundles present a superior evaluation than individual products in all three scales and in both high and lowprice scenarios. The noncomplementary bundles present a similar evaluation to individual products on the three scales and at both price levels. Therefore, while the overall evaluation of bundles with a $45 \%$ discount is superior to the individual products evaluation, it is necessary that the complementarity of bundles is guaranteed in order to ensure the superior evaluations of bundles.

The assignment of discounts in noncomplementary bundles may not have the desired effect because consumers value a bundle when it is composed of complementary products, but the discount should still be significant and assigned to bundles of high price.

\subsection{Managerial Implications}

Hereupon and considering managerial implications, when managers evaluate the implementation of bundles without any discount, they ensure the complementarity of 
it, and still, they carry out the sale of these products individually; i.e., they implement a mixed bundling strategy. In other words, for a particular bundle to be valued, it must be ensured that the products included in it make it possible to use it jointly for a common need or purpose of consumers: for instance, a bundle with air conditioning and the service of installation. After identifying practices or needs that consumers present in their daily lives, corporations must design products or services with the potential to facilitate these practices through the combination of products or services.

Additionally, and according the empirical results, when a manager decides to add a discount on the bundle price, the discount for itself does not ensure higher evaluations of the bundle. Thus, complementarity, price, and discount level should be considered.

\section{Conclusions}

This paper examines the consumer's preference between individual products and bundles and investigates some of the factors involved in bundle characteristics that may affect consumer's preferences. Three factors were applied in this empirical study, complementarity, price level, and discount level.

The empirical results show that in the absence of any discount, bundles do not have a higher evaluation by consumers than individual products, regardless of the type of complementarity and price level. In a scenario where bundles have a lower discount (the authors applied a $20 \%$ rate of discount), results have shown that it is only advantageous to attribute such monetary incentive to the high-priced complementary bundles. Finally, regarding the scenario in which the bundles present a higher discount (the authors applied a $45 \%$ rate of discount), they concluded that it is only beneficial to attribute the discount if the bundle is considered complementary, either for low or high-priced bundles. It was also concluded that for the three scales analyzed (quality, attractiveness, and purchasing intention), the price level has affected consumers' preferences about quality and attractiveness, although the results regarding quality cannot be considered statistically significant.

In terms of theoretical implications, this research contributes to increasing the knowledge regarding the consumers' preferences on bundling in Portugal and gives insights in terms of complementarity and price level. Regarding complementarity, the research shows that complementary bundles have a higher preference than noncomplementary bundles, reinforcing the literature in this area and contributing to a new insight regarding the Portuguese consumer behavior. Therefore, the positive effect of complementarity bundles' valuation is confirmed.

\section{Research Limitation and Further Research Direction}

The present paper has a few limitations that point to directions of further research in this field. First, the arbitrary assignment of levels of bundle price and discount is open to criticism. Secondly, there were included only bundles with two products, and we know that bundles with several products are also common in the marketplace. It would be interesting to develop further research incorporating multiple products taking into account that a bundle with just two products leads to a limitation of the generalizability of the results. Third, the products under evaluation are durable products, so a generalization to all type of products is not possible. A deeper study including non-durable goods would be a complement to the presented conclusions. It would also be interesting to compare the conclusions with data from other countries in order to find cultural issues impacting in the consumers' approach to bundles.

Author Contributions: Conceptualization and Methodology, P.M., P.R., C.M., T.B. and N.D.; writingoriginal draft preparation, P.M., P.R., C.M., T.B. and N.D.; writing-review and editing, R.K.D., Y.L., U.C. and X.Y. All authors have read and agreed to the published version of the manuscript.

Funding: This research received no external funding.

Institutional Review Board Statement: Not applicable. 
Informed Consent Statement: Not applicable.

Data Availability Statement: The data presented in this study are available on request from the corresponding author. The data are not publicly available due to confidentially reasons.

Conflicts of Interest: The authors declare no conflict of interest.

\section{Notes}

1 The term "product" in this definition as well as in the paper refers to products and services in a broad scope.

2 https://www.strategyzer.com/canvas/value-proposition-canvas (accessed on 5 October 2020).

\section{References}

Adams, William James, and Janet L. Yellen. 1976. Commodity Bundling and the Burden of Monopoly. Journal of Economics 90: 475-98. [CrossRef]

Andrews, Melinda L., Ray L. Benedicktus, and Michael K. Brady. 2009. The Effect of Incentives on Customer Evaluations of Service Bundles. Journal of Business Research 63: 71-76. [CrossRef]

Bakos, Yannis, and Erik Brynjolfsson. 1998. Bundling Information Goods: Pricing, Profits, and Efficiency. Management Science 45: 1613-30. [CrossRef]

Bitta, Albert J. Della, Kent B. Monroe, and John M. McGinnis. 1981. Consumer Perceptions of Comparative Price Advertisements. Journal of Marketing Research 18: 416-27. [CrossRef]

Chakravarti, Dipankar, Rajan Krish, Pallab Paul, and Joydeep Srivastava. 2002. Partitioned Presentation of Multicomponent Bundle Prices: Evaluation, Choice and Underlying Processing Effects. Journal of Consumer Psychology 12: 215-29. [CrossRef]

Chen, Ting, Feng Yang, and Xiaolong Guo. 2020. Optimal Bundling in a Distribution Channel in the Presence of Substitutability and Complementarity. International Journal of Production Research, 1-21. [CrossRef]

Chiambaretto, Paul, and Hervé Dumez. 2012. The Role of Bundling in Firms' Marketing Strategies: A Synthesis. Recherche et Applications En Marketing (English Edition) 27: 91-105. [CrossRef]

Dansby, Robert, and Cecilia Conrad. 1984. Commodity Bundling. American Economic Review 74: 377-81.

Darke, Peter R., and Cindy M. Y. Chung. 2005. Effects of Pricing and Promotion on Consumer Perceptions: It Depends on How You Frame It. Journal of Retailing 81: 34-47. [CrossRef]

Derdenger, Timothy, and Vineet Kumar. 2012. The Dynamic Effects of Bundling as a Product Strategy. Harvard Business School. [CrossRef]

Dodds, William B., Kent B. Monroe, and Dhruv Grewal. 1991. Effects of Price, Brand, and Store Information on Buyers' Product Evaluations. Journal of Marketing Research 28: 307-19. [CrossRef]

Drumwright, Minette E. 1992. A Demonstration of Anomalies in Evaluations of Bundling. Marketing Letters 3: 311-21. [CrossRef]

Epstein, Leonardo D., Ignacio E. Inostroza-Quezada, Ronald C. Goodstein, and S. Chan Choi. 2021. Dynamic Effects of Store Promotions on Purchase Conversion: Expanding Technology Applications with Innovative Analytics. Journal of Business Research 128. [CrossRef]

Foubert, Bram, and Els Gijsbrechts. 2007. Shopper Response to Bundle Promotions for Packaged Goods. Journal of Marketing Research 44: 647-62. [CrossRef]

Gaeth, Gary J., Irwin P. Levin, Goutam Chakraborty, and Aron M. Levin. 1990. Consumer Evaluation of Multi-Product Bundles: An Information Integration Analysis. Marketing Letters 2: 47-57. [CrossRef]

Gandal, Neil, Sarit Markovich, and Michael H. Riordan. 2018. Ain't It 'Suite'? Bundling in the PC Office Software Market. Strategic Management Journal 39: 2120-51. [CrossRef]

Goldberg, Stephen M., Paul E. Green, and Yoram Wind. 1984. Conjoint Analysis of Price Premiums. The Journal of Business 57: 111-32. [CrossRef]

Guiltinan, Joseph P. 1987. The Price Bundling Os Services: A Normative Framework. Journal of Marketing 51: 74-85. [CrossRef]

Harlam, Bari A., Aradhna Krishna, Donald R. Lehmann, and Carl Mela. 1995. Impact of Bundle Type, Price Framing and Familiarity on Purchase Intention for the Bundle. Journal of Business Research 33: 57-66. [CrossRef]

Harris, Judy, and Edward A. Blair. 2006. Functional Compatibility Risk and Consumer Preference for Product Bundles. Journal of the Academy of Marketing Science 34: 19-26. [CrossRef]

Herrmann, Andreas, Frank Huber, and Robin Higie Coulter. 1997. Pricing Strategy and Practice Product and Service Bundling Decisions and Their Effects on Purchase Intention. MCB University Press 5: 99-107.

Honhon, Dorothée, and Xiajun Amy Pan. 2017. Improving Profits by Bundling Vertically Differentiated Products. Production and Operations Management 26: 1481-97. [CrossRef]

Kinberg, Yoram, and Ephraim F. Sudit. 1979. Country/Service Bundling in International Tourism: Criteria for the Selection of an Efficient Bundle Mix and Allocation of Joint Revenues. Journal of International Business Studies 10: 51-62. [CrossRef]

Knutsson, Erika. 2011. Bundling for consumers? Understanding Complementarity and Its Effect on Consumers Preferences and Satisfaction. Ph.D. dissertation, Umeå School of Business, Umeå, Sweden.

Kopczewski, Tomasz, Maciej Sobolewski, and Ireneusz Miernik. 2018. Bundling or Unbundling? Integrated Simulation Model of Optimal Pricing Strategies. International Journal of Production Economics 204: 328-45. [CrossRef] 
Kübler, Raoul, Rouven Seifert, and Michael Kandziora. 2020. Content Valuation Strategies for Digital Subscription Platforms. Journal of Cultural Economics 72: 39-63. [CrossRef]

Lawless, Michael W. 1991. Commodity Bundling For Competitive Advantage: Strategic Implications. Journal of Management Studies 28: 267-80. [CrossRef]

Ma, Minghui, and Suman Mallik. 2017. Bundling of Vertically Differentiated Products in a Supply Chain. Decision Sciences 48: 625-56. [CrossRef]

Nagle, Thomas. 1984. Economic Foundations for Pricing. The Journal of Business 57: 3-26. [CrossRef]

Rao, Akshay R., and Kent B. Monroe. 1989. The Effect of Price, Brand Name, and Store Name on Buyers' Perceptions of Product Quality: An Integrative Review. Journal of Marketing Research 26: 351-57.

Rust, Roland T., Inman J. Jeffrey, Jia Jianmin, and Anthony Zahorik. 1999. What You Don't Know About Customer- Perceived Quality: The Role of Customer Expectation Distributions. Marketing Science 18: 77-92. [CrossRef]

Schmalensee, Richard. 1984. Pricing of Product Bundles Gaussian Demand and Commodity Bundling. The Journal of Business 57: 211-23. [CrossRef]

Shaddy, Franklin, and Ayelet Fishbach. 2016. Seller Beware: How Bundling Affects Valuation. Journal of Marketing Research 54: 737-51. [CrossRef]

Sharpe, Kathryn M., and Richard Staelin. 2010. Consumption Effects of Bundling: Consumer Perceptions, Firm Actions, and Public Policy Implications. Journal of Public Policy E Marketing 29: 170-88. [CrossRef]

Sheng, Shibin, Andrew Parker, and Kent Nakamoto. 2007. The Effects of Price Discount and Product Complementarity on Consumer Evaluations of Bundle Components. The Journal of Marketing Theory and Practice 15: 53-64. [CrossRef]

Stigler, George J. 1962. United States v. Loew's Inc.: A Note On Block-Booking. Chicago: University of Chicago Press, vol. 52, pp. 152-57.

Stremersch, Stefan, and Gerard J. Tellis. 2002. Strategic Bundling of Products and Prices: A New Synthesis for Marketing. Journal of Marketing 66: 55-72. [CrossRef]

Telser, L. G. 1979. A Theory of Monopoly of Complementary Goods. The Journal of Business 52: 211-30. [CrossRef]

Todd, Patrick F. 2017. Out of the Box: Illegal Tying and Google's Suite of Apps for the Android OS. European Competition Journal 13: 62-92. [CrossRef]

Vamosiu, Adriana. 2017. Optimal Bundling under Imperfect Competition. International Journal of Production Economics 195: 45-53. [CrossRef]

Venkatesh, R., and Wagner Kamakura. 2003. Optimal Bundling and Pricing Under a Monopoly: Contrasting Complements and Substitutes from Independently Valued Products. Journal of Business 76: 211-31. [CrossRef]

Venkatesh, R., and Vijay Mahajan. 1993. A Probabilistic Approach to Pricing a Bundle of Products or Services. Journal of Marketing Research 30: 494-508. [CrossRef]

Xia, Lan, and Nada Nasr Bechwati. 2021. Maximizing What? The Effect of Maximizing Mindset on the Evaluation of Product Bundles. Journal of Business Research 128: 314-25. [CrossRef]

Yadav, Manjit S. 1994. How Buyers Evaluate Product Bundles: A Model of Anchoring and Adjustment. Journal of Consumer Research 21: 342-53. [CrossRef]

Yadav, Manjit S. 1995. Bundle Evaluation in Different Market Segments: The Effects of Discount Framing and Buyers' Preference Heterogeneity. Journal of the Academy of Marketing Science 23: 206-15. [CrossRef]

Ye, Li, Hong Xie, Weijie Wu, and John C.S. Lui. 2017. Mining Customer Valuations to Optimize Product Bundling Strategy. Paper presented at the 17th IEEE International Conference on Data Mining, New Orleans, LA, USA, November 18-21; pp. 555-64. [CrossRef] 